\title{
DIREITO ALTERNATIVO:
}

\section{A JURIDICIDADE NAS FAVELAS}

\section{TAles Lobosco}

\begin{abstract}
R E S U M O : Embora relegado pelo Estado, o espaço urbano das favelas brasileiras não se caracteriza pela ausência de regras e controles urbanos, mas por uma manifestação específica destes mecanismos. Uma populaçâo social e espacialmente segregada, com pouco conhecimento das leis escritas, mas que sabe, por vivência cotidiana, o significado de justiça e legalidade - foi capaz de estruturar de forma independente a produção do espaço urbano que habitam. Para os habitantes da favela, os direitos não dizem respeito apenas às garantias inscritas na lei e nas instituiçôes, mas ao modo como as relaçôes sociais se estruturam. $O$ distanciamento frente às estruturas formais de controle, que a condição de ilegalidade e informalidade estabelece, proporcionou a organização de estruturas próprias de controle e manutençâo da ordem urbana, que, além de propiciar certa independência de gestão, mostram-se muito mais adequadas às condiçôes e especificidades do espaço que ocupam do que suas equivalentes formais.
\end{abstract}

P A L A V R A S - C H A V E : favelas; espaço urbano; informalidade; ilegalidade urbana; produçâo do espaço; práticas urbanas; direito.

\section{INTRODUÇÃO}

O processo de produção do espaço urbano informal é marcado pelo embate de forças, organizado entre a necessidade de consolidaçáo do espaço de moradia - de forma integrada à cidade, capaz de absorver as oportunidades e vantagens econômicas e sociais associadas a esta - e o invariável distanciamento frente às estruturas formais, que a condição de ilegalidade e informalidade estabelece. Esta situação promove o surgimento de situaçóes ambíguas, nas quais aproximaçóes e distanciamentos simultâneos e de diversas ordens parecem traduzir melhor a interação de espaços formais e informais do que a antiga lógica de segregação e marginalidade.

Náo se trata de uma relação homogênea e inequívoca, mas de uma complexa estrutura, na qual é possível perceber situaçóes de aproximação que podem compreender o fornecimento de mão de obra, o uso de serviços e uma relativa proximidade espacial; e outras nas quais as relações de ilegalidade jurídica, informalidade comercial e precariedade econômica e social promovem um distanciamento marcado, notadamente, pela quase ausência do controle estatal.

Como reação à indiferença dos mecanismos oficiais de controle, versóes locais das estruturas oficiais de poder se organizam a fim de suprir o vazio deixado pelo Estado. Assim, "as camadas populacionais excluídas passam a criar, paralelamente ao Estado, normas a serem aplicadas dentro de seu contexto social, de forma a proporcionar a sua inclusão social" (AMARANTE, 2013, p. 39). Entretanto, tais estruturas não se organizam de forma mimética em relação as suas equivalentes na cidade formal, visto que, em seu processo de gestação, parecem questionar a eficiência e a legitimidade destas 
estruturas, dando origem a formas de organização e autogestão que buscam uma maior conexão com as situações cotidianas vivenciadas por esta população. Visam, portanto, uma estruturação, ainda que de forma tácita, que se organize de maneira especialmente adaptada às necessidades, interesses e possibilidades específicas destes espaços.

Neste sentido, para uma população que pouco conhece das leis escritas e não possui meios para serem assistidos por especialistas, mas que sente e discute diariamente questôes sobre justiça e legalidade - na forma que o senso comum tem a dizer sobre elas e sobre a própria produção cotidiana do espaço que habita -, os direitos não dizem respeito apenas às garantias inscritas na lei e nas instituiçóes; eles se referem, antes de tudo, ao modo como as relaçôes sociais se estruturam, operando como princípios reguladores das práticas sociais e definindo as regras da reciprocidade através da atribuição acordada das obrigaçóes, responsabilidades, garantias e prerrogativas de cada um. Assim, são capazes de balizar as práticas e interaçóes sociais com referência ao que é reconhecido como medida de justiça, ainda que esta seja questionada e negociada através de interesses, valores e opiniōes divergentes (TELLES, 2004).

\section{O DIREITO “ACHADO NA RUA"}

O Estado Legal se corporifica através de um conjunto de normas, abstratas e genéricas, e de órgáos e procedimentos para efetivá-las (MAGALHÃES, 2009), que sejam capazes de promover uma ordem pacífica nas relaçôes sociais humanas. Entretanto, a base imediata desta ordem legal se encontra exclusivamente nos fatos do direito: os hábitos, as relaçôes de dominação e de posse, os contratos e as declaraçôes de vontade. São destes fatos que derivam as regras do comportamento do homem na sociedade (EHRLICH, 1986). Assim, podemos compreender que o direito, por não possuir como relação fundamental a coerção estatal, existiu (e existe) independente do Estado, que, por sua vez, não pode ser entendido como a fonte única e exclusiva de todo o direito (MALISKA, 2001; WOLKMER, 1997).

Neste sentido, Freitag (1990) descreve, a partir das definiçóes de Weber (1984), os padróes de comportamento socialmente regulamentados: o simples uso, através da mera repetição inconsciente de certos comportamentos; o hábito, que se diferencia do primeiro por definir uma repetição que repousa em uma longa vivência; e a tradição, quando o comportamento passa a ter validade, transformando-se em uma prescrição para a ação futura, estabelecendo, assim, um padrão de consciência e regularidade como referência para açóes sociais no futuro. Este desenvolvimento é, entretanto,

1 Segundo Quintaneiro, Barbosa e Oliveira (2002), a diferenciação entre "convenção" e "direito" se estabelece nos casos de uma transgressão: na convenção, a transgressão desencadearia uma desaprovação manifestada diretamente pelos integrantes do grupo; já no direito, ela seria exercida por uma instância especial. rompido na "convenção", ou no "direito", através do surgimento de uma "consciência de que as normas podem ser criadas intencionalmente, sendo produtos da vontade humana e não do arbítrio divino ou da sabedoria dos mais velhos" (FREITAG, 1990, p. 49). Desta forma, a percepção do direito se dissocia da tradição e de padrōes produzidos socialmente e adquire a noção de intencionalidade:

Um tipo de comportamento regulamentado (inconsciente, irrefletido) como o uso é gradativamente substituído por comportamentos conscientes regulamentados (retroativamente, no caso da tradição e progressivamente, nos casos do direito e da convenção). Há, portanto, historicamente, uma tomada de consciência gradativa da norma por parte dos atores, integrantes de sociedades históricas. (FREITAG, 1990, p. 50). 
Se, para Maliska (2001), o direito não deveria ser identificado apenas através das leis, mas refletir as relaçóes sociais de um grupo, independente de sua estrutura legislativa, percebemos, neste último movimento, uma organização no sentido inverso ao da formalização das relaçôes sociais, através de prescriçôes jurídicas específicas. Deste modo, novos fatos do direito surgem através de decisóes dos tribunais e de atos governamentais, produzindo novas normas de comportamento para os homens em sociedade. Possuem, desta forma, uma origem desconectada do comportamento estabelecido e se organizam como tentativa ou processo de manutenção de uma ordem estabelecida, em detrimento de um hipotético "consenso comunitário".

Não basta, todavia, as prescriçôes entrarem formalmente em vigor. As normas, enquanto fato social, só têm poder coercitivo e vigência real se forem (e na medida em que forem) aceitas e seguidas pelos membros integrantes da sociedade (FREITAG, 1990). Por sua vez, os indivíduos somente são capazes de se sujeitar voluntariamente às normas quando reconhecem nestas a necessidade, a utilidade e a legitimidade social (DURKHEIM, 1934).

É neste momento que o "direito das leis" se afasta do "direito vivo", principalmente nas áreas informais e precárias, por conta da complexidade da estrutura oficial, da inadequação às estruturas flexíveis e dinâmicas da informalidade e, muitas vezes, do temor e da submissão a condições violentas de sociabilidade. Em uma situação de pobreza e precariedade generalizadas, somada a uma forte desconfiança frente ao Estado, que se apresenta quase sempre como força coercitiva, vemos surgir um "distanciamento" que ofusca as possibilidades de busca por direitos através dos mecanismos oficiais e uma condição na qual a pobreza legal se soma à material (O'DONNELL, 1999).

Esta situação estabelece as condiçôes necessárias para a atuação de um mecanismo alternativo, que ocupe o espaço deixado pela inadequaçáo do aparato legal. Promove-se, desta forma, o surgimento de "zonas pardas", ou seja, setores, normalmente em áreas periféricas da sociedade, onde o sistema legal sancionado pelo Estado não se mostra presente e, assim, quase não tem efetividade (O’DONNELL, 1999). Segundo Catusso, (2007, p. 128):

O precário desenvolvimento social do país produzindo grandes massas de excluídos propicia o surgimento de comunidades autônomas que buscam implementar regras de convivência próprias, paralelas àquelas disciplinadas pelo direito oficial. A rigor, é a ausência do Estado nesses grupos de excluídos que impossibilita a aplicação do direito oficial.

Considerando que o centro gerador do direito não está na legislação ou na jurisprudência, mas na própria sociedade - através da forma como ele aparece nas relaçóes jurídicas travadas por seus membros -, Ehrlich (1986) designará por "direito vivo" este direito existente, independente do direito legislado, um "direito vigente", que se exerce na prática e domina a vida, ainda que não esteja fixado em prescriçôes jurídicas (CATUSSO, 2007; MALISKA, 2001).

A desconfiança e a percepção da inaplicabilidade das normas oficiais, diante das condiçôes de informalidade, precariedade e flexibilidade urbanas, típicas das áreas informais, abrem espaço à produção e difusão de regras alternativas, construídas de acordo com as necessidades e condiçóes locais. Um direito sob medida, elaborado na tradição do uso e através da noção de justiça elaborada no interior da própria "comu- 
nidade", seja ela real ou simbolicamente construída. Assim, enraizado na sociedade, a prática social se difunde e se transforma em parte constitutiva da ordem social:

[...] quando um fenômeno social, em virtude de sua expansão, transforma-se em fenômeno permanente, a sociedade vê-se obrigada a tomar posição [...] a sociedade deve rejeitar e combater essa nova forma ou então integrá-la na ordem social e econômica geral, por ser um meio adequado para satisfazer às necessidades sociais e econômicas. (EHRLICH, 1986, p. 95).

2 Expressão criada por Roberto Lyra Filho.
O "direito achado na rua" 2 é uma tentativa de caracterizar uma concepção de direito que emerge dos espaços públicos, da rua, através da formação de sociabilidades reinventadas, abrindo a consciência para uma cultura de cidadania e de participação democrática alternativa. Nas palavras de Sousa Junior (2008, p. 5):

Esta proposta está imbuída de um claro humanismo, pois toma o protagonismo dos sujeitos enquanto disposiçáo para quebrar as algemas que os aprisionam nas opressōes e espoliações como condição de desalienação e de possibilidade de transformarem seus destinos e suas próprias experiências em direção histórica emancipadora, como tarefa que não se realiza isoladamente, mas em conjunto, de modo solidário.

Uma das questóes centrais da discussáo do direito alternativo, ou "achado na rua", seria a formulação de uma legislação ordenadora e disciplinadora do uso do espaço, que seja adaptada às condicionantes e circunstâncias físico-territoriais e socioculturais das favelas. Tal postura visaria garantir o desenvolvimento ordenado e racional de tais espaços e, ao mesmo tempo, a marcação da presença do Estado nestas áreas, que frequentemente configuram espaços literalmente excluídos do planejamento e ordenamento das cidades, como se o Estado não buscasse exercer nelas seu papel de regulação legal (MAGALHĀES, 2009).

\section{LIBERDADE COLETIVA E MOVIMENTOS SOCIAIS}

Os seres humanos não nascem livres, mas inseridos em uma rede preexistente de relacionamentos sociais, "como súditos de um império ou membros de uma tribo ou nação, de uma casta ou classe, de um gênero, de uma comunidade religiosa; e os limites de sua liberdade são condicionados por essas circunstâncias" (BOTTOMORE, 1996, p. 424). Desta forma, a liberdade, em seu sentido mais universal, depende de um "complexo de instituiçóes sociais, o qual constitui um tipo particular de ordem social” (BOTTOMORE, 1996, p. 424). Entretanto, a liberdade não é uma subordinação a um destino, mas uma construção histórica que não se produz isoladamente, mas em conjunto. E se ela não existe em si, senão como resultante de práticas efetivamente livres, o direito será comumente a sua expressão, como afirmação histórico-social e modelo avançado de legítima organização social da liberdade (LYRA FILHO, 1982; SOUSA JUNIOR, 2008).

Como a vida humana é necessariamente social, a liberdade dos indivíduos ou grupos implicará, quase sempre, em alguma limitação da liberdade dos outros. Desta forma, a liberdade deveria ser "concebida como um equilíbrio continuamente mutável 
entre as pretensôes rivais de indivíduos e grupos dentro de uma sociedade" (BOTTOMORE, 1996, p. 424). Entender o direito como modelo de legítima organização social da liberdade significa que "o direito se faz no processo histórico de libertação enquanto desvenda precisamente os impedimentos da liberdade não-lesiva aos demais. Nasce na rua, no clamor dos espoliados e oprimidos" (LYRA FILHO, 1986, p.312).

$\mathrm{O}$ direito estatal e o direito paralelo podem ser entendidos como dois aspectos da dialética social, que se caracterizam através de grupos distintos de forças sociais antagônicas e complementares, atuando, em seu interior, forças centrípetas - de coesão - e forças centrífugas - de dispersão (BISOL, 1990; LYRA FILHO, 1982).

No ramo das forças centrípetas, encontramos a ideologia dos grupos dominantes, que busca combater a dispersão que "desconjuntaria a sociedade e comprometeria a segurança da dominaçáo” (LYRA FILHO, 1982, p. 44), aceitando e promovendo, desta forma, apenas mudanças controladas, capazes de serem absorvidas, sem grandes transformações, na estrutura social vigente. Já as forças centrífugas produziriam o direito dos oprimidos, "um direito paralelo ao direito estatal, de onde emerge a ilegitimidade das normas dominantes, tidas como legítimas através de um 'consenso' produzido pelo fato pré-instituído da dominação" (BISOL, 1990, p. 37).

Neste sentido, Eder Sader (1988) trata da dimensão instituinte dos espaços sociais instaurados pelos movimentos sociais através da capacidade de constituir direitos em decorrência de novos processos sociais que eles passaram a desenvolver:

A consciência de seus direitos consiste exatamente em encarar as privaçôes da vida privada como injustiças no lugar de repetiçôes naturais do cotidiano. E justamente a revoluçáo de expectativas produzidas esteve na busca de uma valorização da dignidade, não mais no estrito cumprimento de seus papéis tradicionais, mas sim na participação coletiva numa luta contra o que consideram as injustiças de que eram vítimas. (SADER, 1988, p. 222).

Caracterizados a partir de suas açóes sociais, estes novos movimentos sociais puderam elaborar um quadro de significaçóes culturais de suas próprias experiências, ou seja, do modo como vivenciam suas relaçóes, identificam interesses, elaboram suas identidades e afirmam direitos, organizando-se através de formas de sociabilidade constituídas em relaçóes de reciprocidade cotidianas, que adestram a convivência e legitimam padróes sociais livremente aceitos (SOUSA JUNIOR, 2008; PHARO, 1985). Um processo em que a carência social contida na reivindicação dos movimentos é por eles percebida, por si só, como negação de um direito (SOUSA JUNIOR, 2008).

\section{O DIREITO EM PASÁRGADA}

A sociedade democrática é a única que considera o conflito legítimo, trabalhando politicamente tanto os conflitos de necessidade quanto os de interesse. Assim, constitui-se como uma sociedade verdadeiramente histórica, aberta ao tempo, ao possível, às transformaçôes e ao novo:

Com efeito, pela criação de novos direitos e pela existência dos contra-poderes sociais, a sociedade democrática não está fixada numa forma para sempre determinada, ou seja, 
não cessa de trabalhar suas divisóes e diferenças internas, de orientar-se pela possibilidade objetiva (a liberdade) e de alterar-se pela própria praxis. (CHAUÍ, 2000, p. 561).

Entretanto, para uma parcela desta sociedade, "a descoberta da lei e dos direitos convive com uma incivilidade cotidiana feita de violência, preconceitos e discriminações" (TELLES, 2004, p. 93), elaborando uma espantosa confusão entre direitos e privilégios. Deste modo, a falta de "parâmetros claros para estabelecer um relacionamento social que seja resultado da conexão entre o real e o legal favorece a normatizaçáo informal de práticas sociais reiteradas em comunidades favelizadas" (CORREA, 2010 p. 6).

$\mathrm{O}$ vazio estatal existente nas áreas informais, fruto da inadequação da estrutura governamental para funcionar no ambiente informal, proporciona o surgimento de um direito alternativo, que convive paralelamente (e de modo divergente) com o direito estatal. Desta forma, a favela se torna um pedaço territorial, cuja relativa autonomia decorre, entre outros fatores, da ilegalidade coletiva da habitação, à luz do direito oficial, condicionando de modo estrutural o relacionamento da comunidade com o aparelho jurídico do Estado (SOUSA JUNIOR, 1990; SANTOS, 1980).

Esse distanciamento das ocupaçóes informais em relação ao Estado se estabelece, simultaneamente, a partir dos dois espaços. A cidade oficial não reconhece, e muitas vezes repele, o território informal, que é tido como invasor, irregular e em desacordo com as normas e regras da cidade (urbanísticas e também sociais). Por outro lado, a condição de irregularidade generalizada das construçóes na favela faz o direito oficial ser uma instância temida pelos riscos permanentes que porta: de despejo e demoliçôes. Deste modo, os conflitos criados no adensamento urbano precisavam ser discutidos e solucionados internamente, de modo a não prejudicar a luta coletiva por moradia: "era preciso desenvolver mecanismos normativos e órgãos jurídicos decisórios internos capazes de lidar com essas questôes, de modo a garantir a ordem na favela" (KONZEN, 2006, p. 174).

Vemos surgir nas favelas um direito interno e informal que vigora de forma paralela, não oficial e precária, gerido parcialmente pelas associaçóes de moradores ${ }^{3} \mathrm{e}$ atuando na prevenção e resoluçáo de conflitos no seio da comunidade, que são decorrentes da luta pela habitação no vazio deixado pelas estruturas do Estado.

Este direito, que Boaventura Santos (1980) chamou de direito de Pasárgada, pautagrande importância na gestão deste "direito alternativo", entretanto, outros atores também possuem forte expressão, como traficantes, moradores muito antigos, donos de biroscas, líderes de igrejas, etc.

ria-se e se legitimaria através da compreensão do senso comum, da tradiçáo das práticas internas e das lógicas internalizadas que, embora subjetivas e ambíguas, seriam baseadas na antiguidade e na necessidade (SOUSA JUNIOR, 1990). Um sistema de gestáo interna que exige boa dose de entendimento, mediação e bom senso. Um procedimento argumentativo de mútua cedência, e acordos com limites definidos pelo mediador, que busca não apenas decidir o conflito, mas sim "construir, aos poucos, uma decisão que fosse aceita pelas partes e pela comunidade" (KONZEN, 2006, p. 178).

Uma estrutura jurídica formada no enfrentamento do estigma e da segregação existentes em torno da favela, onde a situação de posse defectiva do terreno e as construçôes edificadas em desacordo com as regras urbanísticas previstas agem simbolicamente sobre os moradores dos espaços informais, forjando-lhes a noçáo de que não possuem o direito de recorrer ao Estado para reivindicar ou garantir seus direitos. Conforme Santos (1980, p. 114):

A expressão "nós éramos e somos ilegais", que, no seu conteúdo semântico, liga o status de ilegalidade com a própria condição humana dos habitantes de Pasárgada, pode ser in- 
terpretada como indicação de que nas atitudes destes para com o sistema jurídico nacional tudo se passa como se a legalidade da posse da terra se repercutisse sobre todas as outras relaçôes sociais.

Essa ausência de reconhecimento oficial leva a considerar suas demandas como externas à abrangência estatal, de onde "decorre a necessidade de buscar um 'órgão' que não só os reconheça, mas igualmente se constitua parte integrante de todo o arranjo comunitário" (CORREA, 2010, p. 9).

Ainda que os próprios moradores da favela façam distinçôes rígidas entre as normas que valem dentro e fora dela, o espaço da favela se mostra amplamente regulado. A questão do "direito alternativo" não envolve apenas a posse da terra, mas toda a organização social do espaço e suas irregularidades. Estas, devido a suas dimensôes, tornam-se, ao mesmo tempo, difusas e estruturantes do espaço, forjando uma duplicidade jurídica que funciona paralelamente ao direito oficial brasileiro (SANTOS, 1980).

\section{A Lógica da Necessidade E O DIREITo de ANTIGUIdAdE}

Em uma estrutura em que a propriedade do espaço não é fundamentada por títulos imobiliários, mas confirmada pela legitimação social, sua conquista é marcada por um ato desbravador, elaborado como gesto coletivo e respaldado pela necessidade de um grupo por espaços de moradia. Assim, quanto mais incipiente, mais precária e instável a ocupação e maiores os riscos de remoçấo, sujeitando esta populaçáo à perda do investimento despendido na construção da localidade.

Neste sentido, ainda que a legitimação da propriedade esteja fortemente mercantilizada, ela oscila entre a percepção da necessidade, expressa na precariedade partilhada, e a percepção do trabalho embutido na ocupação e resistência, que possibilita a consolidação e permanência da localidade.

A favela não é "terra de ninguém", quanto mais consolidada maior sua estrutura reguladora interna, de forma que construir ali, mesmo em seus espaços remanescentes, não é uma condição livre. "A admissão do novo morador é negociada e autorizada por alguém com prestígio. Somente os nascidos e criados no morro podem construir domicílios sem autorizaçáo" (LESSA, 2005, p. 304). Nas palavras de uma moradora de Novos Alagados ${ }^{4}$ :

Aqui era vazio, não tinha casa nenhuma, aqui era um matagal, [...] pode se dizer que desde que a gente veio morar aqui, a gente tomava conta desse terreno aí. Quando o dono veio fez um vãozinho, deu uma parte do terreno pro meu marido pelo tempo que a gente tomava conta, e outra parte ficou para o filho do rapaz (Altiva).

Neste processo, o próprio valor do terreno é fortemente determinado pela condiçấo da ocupação, pelo estágio de consolidação, pela disponibilidade de terras e pela densidade da ocupação, em uma relaçáo na qual o espaço vazio e o "mato" representam uma situação desvalorizada, não apenas pela oferta abundante de terras em condiçôes semelhantes, mas por simbolizar a terra "bruta", pouco apropriada e consolidada, muito suscetível a movimentos de repressão à ocupação e pouco atendida por infraestrutura e serviços. A fala de um morador de Novos Alagados descreve esta situaçáo de grande desvalorização das terras:
4 Os depoimentos citados ao longo do texto foram colhidos em visitas de campo às favelas de Novos Alagados, em Salvador (BA), e Santa Marta e Babilônia, no Rio de Janeiro (RJ), entre maio de 2008 e fevereiro de 2011. 
Aqui o pessoal cada qual tem seu espaçozinho, mas deveria ser dos moradores que estavam no começo, deveria ser meu, deveria ser dos meus irmãos, dela, porque nós tivemos vários terrenos, mas trocamos por... trocava por besteira. E se não trocasse ia valer o que? (Gilson).

Não é apenas a antiguidade e os "serviços prestados" que orientam a legitimação da posse. A existência, explícita e visível, da necessidade de ocupação do espaço também seria capaz de garantir prerrogativas especiais. Assim, não habitar imediatamente um espaço demarcado faz a ocupação ser entendida como não necessária, permitindo, deste modo, que o lote vazio seja passível de uma nova intervenção. Uma moradora de Novos Alagados apresenta sua experiência neste processo:

Eu soube que tinha esta invasão aqui, mas quando eu cheguei aqui já tava tudo tomado, tudo marcado. Então tinha esse terreninho aqui, que já tinha dono, né? Já tinham marcado, mas ninguém veio morar. Se não veio não tá precisando né? Então eu fiquei aqui, era só uma lona, com uns paus, mas eu fiquei, com minhas filhas, tentaram me tirar, mas o pessoal me apoiou porque sabia que eu tava precisando, que eu não tinha marido nem trabalho. (Dona Francisca).

Se a necessidade pode ser significativa na manutenção da posse, ela também pode ser fortemente contestada quando não se mostra ou deixa de ser efetiva. Uma moradora da Babilônia explicita como as dimensóes da moradia podem ser compreendidas como expressão desta necessidade, ou da falta dela:

Essa casa aqui do lado é de um primo meu, ele estava precisando e a gente cedeu um pedaço do quintal, não cobramos nada não, era pra ajudar, sabe. Mas a casa dele ficou muito grande, isso não é uma casa de quem tava precisando! Agora eu náo posso levantar meu segundo andar porque vai tapar a janela dele (Dona Ana).

A legitimação através da necessidade se organiza como uma "outra" ética espacial, produzindo um espaço urbano com características específicas. Entretanto, "erra quem náo percebe que as regras da favela, apesar de socialmente inclusivas, não são equalizadoras. A diferenciação pelo econômico é respeitada" (LESSA, 2005, p. 304), em uma relação através da qual a expressão da hierarquia de poderes interna ocorre de modo quase autoritário. Se, por um lado, a necessidade justifica certas prioridades, como a flexibilização espacial ou o atendimento preferencial - no caso de uma intervenção estatal, dedicado às habitaçóes mais precárias -; por outro, percebemos que a condição economicamente dominante cria prerrogativas específicas, que se desenvolvem na exploração interna da pobreza. A heterogeneidade, que é inerente à favela, reproduzirá em seu interior os mecanismos de exploraçấo econômica consagrados na cidade formal, como uma caricatura da sociedade global, onde os que dispóem de algum poder "prosperam reexplorando os pobres na favela: o dono da birosca, a comissão de energia elétrica, o senhorio do barraco, etc." (LESSA, 2005, p. 304).

O campo de manobra dos indivíduos para a elaboração de suas condiçóes sociais e manipulação dos signos de estigma e status se articula de acordo com o conceito weberiano de "grupos de status", no qual o principal signo de prestígio parece ser ligado ao território, por sua localização e legitimação pelo tempo de moradia. Uma situação onde os "estabe- 
lecidos" de Elias e Scotson (2000) ocuparão as partes mais prestigiadas e antigas da favela. "Tais critérios ajudam a compor uma alteridade calcada não somente na ideia de status superior como de uma 'virtude humana' mais elevada" (MOUTINHO, 2002, p. 241).

Assim, respaldados por uma legitimidade conquistada no tempo de permanência e por uma estrutura socioespacial elaborada na organizaçáo existente, a ocupação prévia do espaço é garantidora de direitos fundados na antiguidade, que parece se estabelecer de forma clara quando se trata de novos moradores, mas que deixam grande brecha aos arranjos locais e às negociaçóes específicas quando se tratam de moradores igualmente antigos.

O diálogo com uma moradora do Santa Marta, transcrito a seguir, permite perceber que a complexidade de situaçóes, como as representadas nas figuras 1 e 2, não admite uma solução única e pré-determinada:

- Se o vizinho da frente resolver construir o segundo andar dele, ele não vai poder, porque aí vai fechar nossa janela.

- Mas ele também não tem direito de fazer o segundo andar dele?

- Ter, ele tem, mas não pode fechar a nossa janela. Senão, como é que a gente fica?

- Mas foi a casa de vocês que avançou sobre a viela, caso contrário haveria espaço para abrir a janela.

- Foi, mas a gente já estava aqui, meu pai construiu isso aqui há muito tempo, este segundo andar já está aí há muito tempo.

- Então, neste caso o que aconteceria?

- Ah, não sei não, ia dar briga, ele não pode fechar nossa janela assim, acabar com nossa vista e pronto. (Diálogo com Maria de Lurdes).

Figura 1: A Casa de Maria de Lourdes no Morro Santa Marta

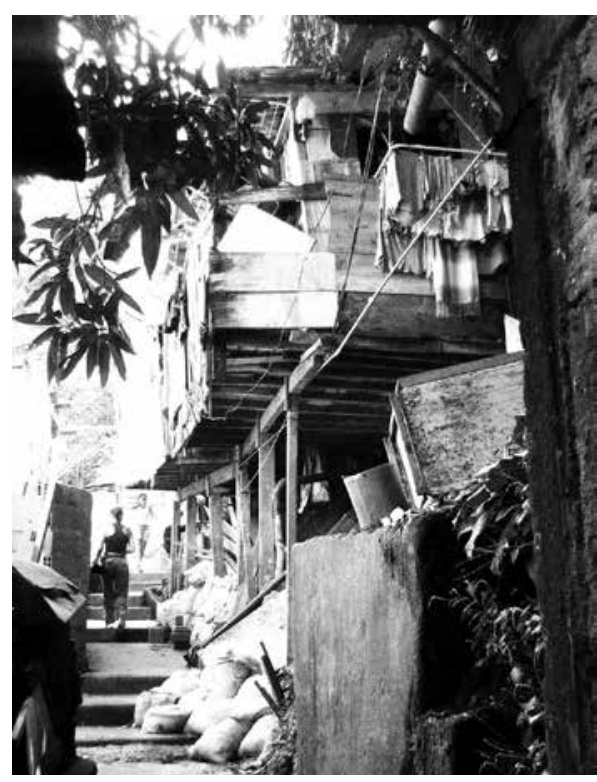

Fonte: foto do autor.
Figura 2: A funcionalidade básica restringe as possibilidades de expansão das novas casas

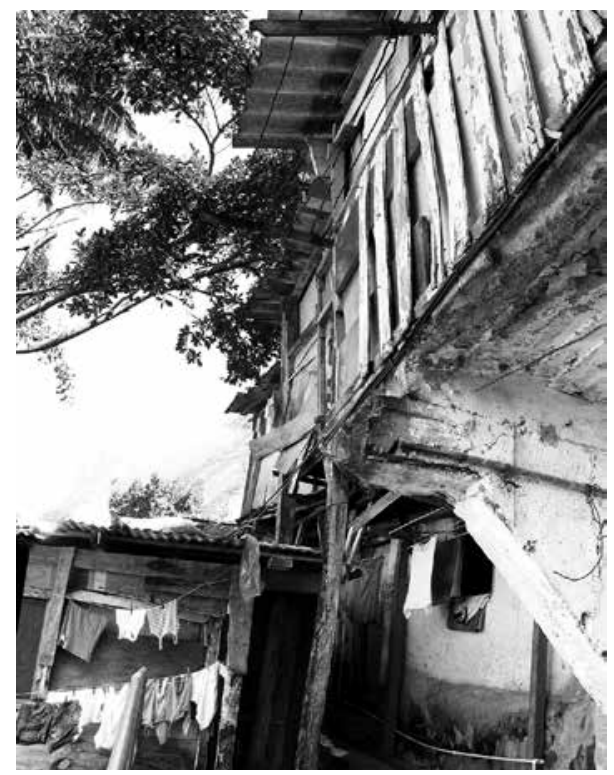

Fonte: foto do autor. 


\section{As Associações de MORAdores}

Arbitrar conflitos e servir como mediadora não era uma das atribuiçóes previstas para as associaçôes de moradores, mas se tornou, visto que a liberdade construtiva, alheia aos limites urbanísticos impostos pelos códigos estatais, produz uma relação de domínio pleno da parcela de solo ocupada. Nas palavras de um morador de Novos Alagados: "No meu terreno, eu faço o que eu quiser, no interior destas quatro linhas, daqui pra dentro quem decide o que pode sou eu" (Jorge).

Esta situação, ainda que aceite, tácita e amplamente, os princípios de antiguidade, funcionalidade e necessidade, produz eventuais interferências na percepção da liberdade individual entre vizinhos, que exigem uma negociação mais complexa e marcada por certa neutralidade.

Da mesma forma, a ilegalidade coletiva, em relação à posse da terra, ainda que não houvesse impedido a ampla comercialização dos bens imóveis, produziu a necessidade de se estabelecer meios de proteção jurídica a estas transaçôes, assim como de organizar e estruturar um registro informal destas posses (KONZEN, 2006). É neste momento que a ocupaçáo e a propriedade da terra, ilegais segundo o direito do asfalto, convertem-se em propriedade legal e efetiva, conforme o direito alternativo da favela, que passa a criar suas próprias instituiçóes normativas.

Diante da inaplicabilidade das posturas municipais para edificaçóes nestas localidades, as associaçôes, como instâncias locais e informais de ordenamento, produzem uma versão oral do código municipal de obras e de suas diretrizes administrativas (JUNQUEIRA; RODRIGUES, 1992). É através do esforço de legalizar aquilo que o Estado se vê impedido de fazer que as associaçóes estabelecem um registro informal, posicionando-se como instituição local capaz de estruturar mecanismos paralegais de reconhecimento.

Assim, a compra e venda de imóveis na área de favela só se torna válida, e reconhecida publicamente, quando intermediada pelas associações de moradores. Via de regra, as transaçôes são realizadas perante seu próprio presidente, passando a constar nos registros imobiliários informais que esta administra: "constitui um procedimento reconhecido por todos e que oferece segurança consistente na legitimação do adquirente em face de todos os moradores atuais e futuros daquela favela". [Trata-se de um ato que], "[...] à luz dos costumes locais, confere eficácia erga omnes à compra do imóvel” (MAGALHÃES, 2009, p. 92).

Para Konzen (2006, p. 179):

50 direito costumeiro define-se como o conjunto de regras que se estabeleceram pelo costume ou pela tradição. Entretanto, para que o costume seja admitido como tal, é indispensável que se tenha fundado em uso geral e prolongado, havendo a presunção de que o consenso geral o aprovou (Magalhães, 2009, p.92).
A legitimidade da Associação, como fórum jurídico, consolidava-se pelo uso de artefatos: sede física da associação, móveis, papelada, estatutos, códigos, máquinas de escrever, carimbos etc. $\mathrm{Na}$ dialética entre a proximidade da Associação - como órgão de expressão sociopolítica emergente do seio da própria comunidade - e a distância necessária para exercer o papel de fórum jurídico, o efeito simbólico oferecido pelos artefatos era o de garantir um mínimo de alteridade que lhe permitisse decidir acerca dos litígios.

Ainda que a associação não seja investida oficial e publicamente desta função pelo Estado - de forma que, embora não seja ilícito, o ato de registro na entidade não seria de modo algum obrigatório -, a existência desta instância como direito consuetudinário $^{5}$ das favelas (MAGALHÁES, 2009) faz com que a chancela (ou reconhecimento) 
da associação seja considerada como a "oficialização" máxima disponível para o espaço da favela, uma formalidade do informal "instituída pelos costumes estabelecidos naquela parcela da sociedade, válida e exigível específica e unicamente para os imóveis situados em sua “jurisdição"” (MAGALHĀES, 2009, p. 97).

Se, à luz da legislação em vigor e a despeito do reconhecimento da associação, os proprietários seriam apenas possuidores dos imóveis, dada a posse defectiva do terreno, os moradores das favelas reconhecem plenamente os donos de terrenos como "proprietários". À luz da economia e legalidade próprias ${ }^{6}$, estabelece-se um procedimento que só tem valor interno e que não é o mesmo que entende o Estado (ou os não-moradores de favela), admitindo, assim, "que há regras, instituiçôes, procedimentos e obrigaçôes que são vigentes apenas fora da favela, não dentro, e vice versa" (MAGALHÃES, 2009, p. 93).

Ao estipular uma instância de registro, que não seja apenas a afirmação de propriedade pelo morador, e ao estabelecer um histórico das transaçóes que permite auferir a veracidade das reivindicaçôes de propriedade, que, à semelhança dos registros oficiais, observa o chamado princípio da continuidade registrária, "a Associação demonstra ter o idêntico cuidado de somente aceitar e reconhecer uma venda caso seja realizada por aquela pessoa que, em seus registros, consta como 'dono' do imóvel” (MAGALHÂES, 2009, p. 93). Fruto de uma necessidade lógica ou operacional interna, ou através de uma comunicação discreta e imperceptível entre os costumes vigentes na favela e os rituais e procedimentos legais definidos pelo Estado, esta mimetização demonstraria uma tentativa de aproximação - através da apropriação fragmentária das instituições do Estado - a fim de legitimar, interna e externamente, as próprias instituições da favela (MAGALHÃES, 2009). Nas palavras de Santos (1980, p. 110):

Muito em geral pode dizer-se que não se trata de uma relação igualitária, já que o direito de Pasárgada é sempre e de múltiplas formas um direito dependente em relação ao direito oficial brasileiro. Recorrendo a uma categoria da economia política, pode dizer-se que se trata de uma troca desigual de juridicidade entre as classes cujos interesses se espalham num e noutro direito.

As ordens jurídicas "estatal e favelar se encontram em um contínuo e conflituoso processo de diálogo, havendo diversas formas em que uma é condicionada pela outra, ou em que uma se constitui recorrendo à incorporação de elementos originários da outra" (MAGALHÂES, 2009, p. 99). O que vale "fora" se torna exemplo e referência, entretanto, o que acontece "dentro" precisa ser aproveitado para ali intervir: um processo de juridificação híbrida construída no embate, no diálogo e na contradição com aquela posta pelo Estado.

\section{A REGULAÇÃo MUNICIPAL}

$\mathrm{Na}$ esteira dos projetos de intervenção urbana do Favela Bairro, criado em 1993 para reurbanizar e dotar de infraestrutura básica as favelas cariocas, a Prefeitura do Rio de Janeiro instaura, em 1996, o Posto de Orientação Urbanística e Social (Pouso), com o objetivo divulgado de consolidar estes novos bairros através da orientaçáo da execução de novas construçôes e da fiscalização urbanística e edilícia. Inicialmente criado como um braço educativo do programa de urbanização, voltado ao
6 De acordo com Cesar, re presentante da Associação de Moradores da Babilônia, embora emitam o registro de imóveis, sabe-se que ali dentro a propriedade do solo não é real, mas, ainda assim, transferem-se as casas, o uso, a ocupação, etc., baseando-se em uma aceitação externa da legitimidade do que se faz ali dentro. 
7 Arquiteta responsável pelo projeto de urbanização do Morro da Babilônia.

8 Presidente do Instituto Brasileiro de Análises Sociais e Econômicas (Ibase) e morador do Santa Marta. monitoramento do espaço construído nas comunidades, na prática, o Pouso marca o início do processo de regulamentação e controle estatal sobre as construçóes e o espaço urbano da favela.

Entre 2000 e 2013, a prefeitura do Rio de Janeiro editou 27 decretos definindo normas de uso e ocupação do solo em favelas. Estes decretos apresentam grande similaridade e são marcados pela simplicidade dos parâmetros urbanísticos. Definem, além das condições mínimas de habitabilidade, a identificação das áreas públicas e de risco, e, através de subzonas, os gabaritos máximos permitidos, congelando as construçôes da favela pela inclusão de todas as áreas livres como "áreas impróprias para edificação".

A intenção declarada seria de regularizar todas as edificaçóes existentes que se enquadrem nas normas estabelecidas, entretanto, os próprios decretos trazem um levantamento das construçóes existentes, demonstrando que o gabarito da maior parte das construçóes nas favelas se encontra acima dos limites estabelecidos.

Adicionalmente, o decreto 30.985, de agosto de 2011, completa este congelamento ao restringir as construções nas favelas a obras de melhoria das condiçôes de habitabilidade e higiene, impedindo qualquer aumento do gabarito, expansão lateral ou constituição de novas unidades habitacionais, mesmo que dentro dos limites do decreto vigente no local.

O caráter minimalista da legislação parece menos associado a uma adaptação às instâncias regulatórias internas e aos mecanismos de autogestáo elaborados na favela do que à despreocupação com o padrão de qualidade, contrastando com a legislação da "cidade formal", que o teria inspirado (MAGALHÃES, 2011).

Em 2010, um novo programa de urbanizaçáo de favelas, lançado pela Prefeitura do Rio de Janeiro, marca a postura em construção de "evitar reconhecer a favela como um território peculiar, preferindo situá-la como parte comum da cidade” (BURGOS, 2012, p. 384). O questionamento à manutenção da especificidade construtiva passa a ser uma postura projetual, que busca, então, estender os limites do urbanismo formal à favela: "O problema todo do crescimento da favela é essa flexibilidade que existe, você não tem limite pra flexibilidade [...] e você não pode esquecer que estas pessoas estão vivendo na cidade" (Solange ${ }^{7}$ ).

A imposição do conjunto normativo estatal a uma estrutura social estabelecida ao longo de décadas de organização autônoma gera, naturalmente, um forte estranhamento e intensas reações, como nos mostra a moradora do Santa Marta: "Eles pensam não tá atrapalhando ninguém, então vou fazer [...], mas agora o Pouso tá aí e para a nossa obra. E eles não aceitam, eu também não aceitaria” (Nanã).

O processo de introdução de normas legais é entendido pelo poder público como uma necessária "transformação da cultura local, a fim de se definir uma nova ética e um novo código de conduta social” (MAGALHÂES, 2011, p. 12). A falta de um processo participativo de discussáo das normas internas faz com que o Pouso seja visto apenas como um elemento de controle e de restrição: "Ele aparece para a favela para proibir: Não, aqui não pode. Aí tem um auto de interdição: não pode construir... Mas por que não pode construir?” (Itamar Silva ${ }^{8}$ ). 
Com o avanço da criminalidade e a crescente organização das quadrilhas de ban(1992). didos territorializadas nas favelas, vemos, a partir da década de 1990, a juridicidade mediacional das Associaçôes de Moradores, e sua legitimidade como instância ordenadora do espaço, ser substituída, ao menos parcialmente, por uma juridicidade fundamentada na violência exercida pelo crime organizado. $\mathrm{O}$ "poder de polícia" que os criminosos dispõem contra os que se arriscam a agir em suas bases territoriais, através de uma violência subterrânea e cotidiana, aflige as populaçôes marginalizadas e obriga-os a estabelecer, como estratégia de sobrevivência, compromissos com o crime organizado (JUNQUEIRA; RODRIGUES, 1992).

Diante da frequente dificuldade no atendimento, por parte da polícia, a seus problemas imediatos, muitos moradores acabam recorrendo aos chefes das quadrilhas do tráfico para resolver questóes pessoais, suprir necessidades imediatas e arbitrar conflitos com vizinhos. Uma solução que faz emergir um elemento complicador nesta relação, ao oferecer uma forma de legitimação do poder dos traficantes nesses locais e fornecer embasamento às teses de "conivência", que afirmam uma consciente "escolha da 'lei do tráfico' ao invés da 'lei da nação' como fundamento da sociabilidade nas favelas" (LEITE; OLIVEIRA, 2005, p. 21).

A polícia, sob suspeita generalizada de comportamento ilícito, não estabelece uma relação de confiança e legitimidade com os setores populares, que se percebem excluídos do jogo de influências que efetivamente determina a ordem nestas localidades. Por outro lado, na visão das forças policiais, as restrições da lei atuam, muitas vezes, como entraves para a efetiva manutenção da ordem nestes territórios, considerando o frequente recurso à força e à violência como parte de sua missão de combate ao crime. Comprometem, desta forma, a percepção da legitimidade do Estado como defensor de direitos dos cidadáos, e reforçam o entendimento de que os direitos civis não vigoram nas favelas.

Se, por um lado, o Poder Judiciário é percebido como uma instância mediadora de conflitos exclusiva das elites brasileiras, e, por outro, a polícia - à qual restaria, na prática, a tarefa de instância judiciária dos pobres (OLIVEIRA, 1985) - possui uma postura que afirma "pedagogicamente", através de abordagens violentas e arbitrárias, que as regras do jogo são construídas às margens da lei (JUNQUEIRA; RODRIGUES, 1992, p. 12), vemos emergir uma ruptura dos precários vínculos de confiança, que seriam capazes de regular a relação das instituiçóes legais de poder com as classes populares. Mais do que a estranheza desenvolvida pela população pobre frente ao aparato jurídico estabelecido, é o sentimento de repulsa, provocado pelas práticas corruptas, arbitrárias e violentas da polícia, que vai explicar o recurso a outras "forças de ordem” nas favelas (JUNQUEIRA; RODRIGUES, 1992).

Em meio à indefinição de instâncias reguladoras, as Associaçóes de Moradores assumem um papel de ator normativo, ao menos em relação ao ordenamento das edificaçóes, regulando as transferências de propriedade e intermediando a resoluçáo de conflitos. Entretanto, entre o vazio deixado pelo Estado e o frágil estabelecimento dos vínculos comunitários dialogais, a imposição forçada da juridicidade violenta se mostra muito mais abrangente e ampla ao exercer, de forma arbitrária, um "poder de polícia" imposto transversalmente à estrutura social da favela, capaz de "distribuir justiça" de forma rápida e automática, com penalidades severas e desumanas em 
sentenças irrecorríveis que levam frequentemente ao banimento da comunidade, à mutilação ou à morte (JUNQUEIRA; RODRIGUES, 1992).

Ainda que a "juridicidade violenta" exerça algum controle da ordem social local, restringindo pequenos delitos na "comunidade" e atuando na resoluçáo de conflitos, náo se pode falar no estabelecimento de uma contrapartida ao controle social estatal ou na expressão de um espírito comunitário em reação a um ambiente hostil. A ética é a da autopreservação, e a manutenção da ordem se faz segundo seus próprios impulsos e interesses. Uma lógica na qual a demonstração ocasional de força, aplicada arbitrariamente aos que venham a prejudicar seus interesses, serve de suporte à imposição de uma severa lei do silêncio (JUNQUEIRA; RODRIGUES, 1992).

Entretanto, se esta situação permite aos moradores, pragmaticamente, usufruírem de certa tranquilidade na comunidade - pela ausência de assaltos e outros crimes que não interessam ao tráfico - esta relação é baseada apenas no benefício imediato associado à maior segurança e previsibilidade de açôes e não segundo uma concordância ideológica: "se existisse um pacto formal entre os traficantes e a população local, os motivos deste acordo não seriam os do homo sociologicus da sociologia clássica, movido por normas, mas sim do homo economicus, movido pelo interesse" (JUNQUEIRA; RODRIGUES, 1992, p. 15).

\section{A "PACIFICAÇÃo"}

A partir de 2008, com a chegada da Unidade de Polícia Pacificadora (UPP) em muitas comunidades, junto com a publicizada retomada estatal do território, todo um conjunto de questôes que eram determinadas e, de certa forma, ordenadas pelo tráfico passam a ser, por herança simbólica, remetidas à UPP, que assume o papel de ente regulador das questôes rotineiras daquela comunidade.

Muitas questôes assistenciais que eram exercidas na comunidade, ainda que erraticamente, pelos grupos armados, como o fornecimento de cestas básicas e até mesmo a solução emergencial de problemas de infraestrutura, não encontram paralelo na UPP. Mas o vazio regulatório e as lacunas deixadas pelo grupos criminosos acabam instando a UPP a assumir a administração de problemas para os quais não estava preparada, como a mediaçáo de disputas, resolução de conflitos, fiscalização e tomada de decisão em assuntos relacionados à vida comunitária. A prática recorrente dos policiais da UPP, de ocupar os mesmos locais da comunidade previamente ocupados pelas "bocas", reforça essa situação.

A maior parte dos moradores reconhece os benefícios trazidos com o processo de pacificação, como a redução dos riscos de incursôes violentas e a recém descoberta liberdade de circulação, mas também questiona as práticas truculentas e a ostensividade da atuação policial, bem como a regulação excessiva de certas atividades comunitárias, como exemplifica a fala de Itamar Silva: "Claro que existem melhorias, ninguém é maluco de dizer que quer viver sob ameaça constante de uma guerra ou um confronto de grupos armados. Mas a questão é: qual é o limite de atuação dessa polícia? Quais são as suas tarefas?"

Essa indefinição a respeito do papel das UPPs na vida da comunidade é marcada por uma forte desconfiança quanto à perda da autonomia na resolução de seus próprios problemas através do diálogo, principalmente diante da percepção da ampliação do papel da polícia enquanto agente regulador da vida social da comunidade (BUR- 
GOS et al., 2011). Questionando-se, assim, o papel da UPP na criação dessas normas ou regras de convivência em uma comunidade que sempre teve vida e regras próprias.

Essa situação se torna especialmente delicada ao se tratar de questôes relativas à regulamentação da "diversão" e do lazer, como, por exemplo, quando a UPP regulou o volume sonoro e a realização de festas e eventos, muitas vezes proibindo os bailes funk, ainda que alegasse estar "aplicando as regulamentaçôes do Estado e protegendo o direito ao descanso dos moradores que queriam silêncio nos fins de semana" (BURGOS et al., 2011, p. 74).

Outro fator que merece atenção é a desconfiança construída através da longa convivência com o tráfico, seja da polícia em face de uma suposta cumplicidade dos moradores da favela ou dos moradores frente a uma força policial que sempre fez incursôes violentas nas favelas, sem se preocupar com a integridade física da população. O histórico de truculência e opressão, aliado às formas abusivas da abordagem policial rotineira na ação da UPP, reavivam a memória da sujeição aos impulsos e ânimos de homens fortemente armados, constrangendo as possibilidades de diálogo e aproximação, através do questionamento se a opressão das gangues do tráfico foi meramente substituída pela ocupação da Polícia Militar (BURGOS et al., 2011).

\section{CONCLUSÃO}

A condição social e espacialmente segregada, aliada à fragilidade econômica, produziram um paradoxo: as desequilibradas relaçóes de poder impunham a ordem estabelecida e, ao mesmo tempo, impossibilitavam setores da população de funcionarem integralmente de acordo com ela. Desta forma, um rompimento se tornou inevitável, e com ele se estruturou uma condição precária de habitar a cidade, ao mesmo tempo que propiciou o surgimento de práticas urbanas específicas, tanto como forma de adaptação às condiçóes existentes como fruto de uma possibilidade de habitar pautada, ainda que sob o imaginário da cidade formal, por valores e códigos próprios.

Nesta situaçáo identificamos o surgimento de práticas específicas, organizadas de forma a possibilitar o funcionamento e o desenvolvimento de uma estrutura urbana que oscila entre as possibilidades de integração com a cidade e as táticas de produção e uso do espaço, elaboradas segundo uma lógica própria, refletindo valores como necessidade, antiguidade, possibilidades construtivas, inserção em redes sociais e acesso a trabalho e serviços.

O processo de criação de estruturas comunitárias complexas, capazes de suprir o vazio deixado pelo Estado, não é evidente nem fluido. Até que uma estrutura se legitime, os conflitos acabam sendo resolvidos de forma violenta, devido a uma "dificuldade estrutural enfrentada pela comunidade no acesso aos meios de controle e às ordenações oficiais - essencialmente a polícia e os tribunais - e à inexistência de mecanismos comunitários alternativos capazes de suprir essa carência" (KONZEN, 2006, p. 175).

Entretanto, diante do vazio estatal, assistimos, via de regra, ao estabelecimento de novas estruturas de controle, que podem ser mais ou menos independentes e autogeridas. Estas estruturas se sobrepóem e se somam, formando uma complexa teia estruturante do espaço urbano, que articula as diversas camadas, desde regras tácitas formadas na compreensão do senso comum e de legitimidade em relação a um espaço 
Tales Lobosco é arquiteto e urbanista pela Universidade de São Paulo (USP); mestre pela Université de Tours; doutor em Arquitetura e Urbanismo pela Universidade Federal da Bahia (UFBA); professor adjunto do Curso de Arquitetura e Urbanismo da Universidade Federal de Mato Grosso (UFMT), Brasil. E-mail: tales@lobosco.com.br.

Artigo recebido em janeiro de 2014 e aprovado para publicação em abril de 2014. "conquistado", até as Associaçóes de Moradores, que representam uma formação mais estruturada das articulaçôes informais.

Nos processos de gestão, negociação e construção das formas de convivência, o problema parece não ser a existência de regras, mas a legitimação dessas regras, para que sejam pactuadas e reconhecidas como democráticas. De qualquer modo, "não dá para pensar a 'cidade formal' sem contemplar que nela existe uma grande dimensáo informal e a mesma coisa na dita 'cidade informal', que tem toda sua formalidade" (SARAYED-DIN, 2009, p. 26).

Gestada neste delicado equilíbrio, a favela apresenta morfologia e definição específicas, configurando-se como um conjunto com constituição própria que se diferencia do resto da cidade: no que tange às práticas construtivas usuais na favela, os arranjos legislativos vigentes não suportam a criatividade social do processo de produção espacial autonomamente legislado, construindo, assim, um "impedimento jurídico" em reconhecer o direito de propriedade das pessoas que construíram suas moradias conforme as práticas sociais partilhadas no local.

Mas não podemos deixar de considerar que os valores de mercado resultam de uma série de informaçóes que a comunidade julga como indicadores de maior ou menor importância econômica. Desta maneira, valorizam-se sensivelmente aqueles imóveis que possuem "registro" ou com condiçôes para tal - ou que são derivados de práticas contratuais. É como se a "registrabilidade" "legalizasse" a situação originária da ocupação (CORREA, 2010 p. 8).

Todo o processo de regularização fundiária e fornecimento de serviços, somado à nova situação estabelecida com a UPP, promoveram uma grande valorização dos imóveis das favelas ocupadas. Contudo, as contrapartidas que recaem sobre os moradores, traduzidas em uma série de obrigaçóes econômicas, políticas e morais e na necessidade de elas se adequarem às normas urbanísticas e edilícias, têm provocado conflitos entre os moradores e o poder público, decorrentes "da experiência de adaptação a uma nova realidade e de internalização de novas regras" (CUNHA; MELLO, 2011, p. 392). Além da repentina exigência de diferentes práticas sociais, seus moradores se confrontam com uma virtual transformação das favelas por processos de gentrificação, e com eles o medo de não poderem mais permanecer nesses espaços.

Assim, ainda que signifique um novo estágio de organização política da cidade, que busca tomar o controle da cidade de forma mais ampla, seu efeito poderá ser a "expulsão dos atuais moradores das favelas mais valorizadas da cidade, não pela mão bruta do Estado, mas pela máo invisível do mercado" (BURGOS, 2012, p. 389). E uma situaçẫo de "expulsão branca" parece sugerir uma intenção original que oscila entre as possibilidades de integraçáo real e aquelas de apropriação destes espaços por outros segmentos sociais.

\section{BIBLIOGRAFIA}

AMARANTE, F. O pluralismo jurídico e o direito de laje. Revista Magister de Direito Ambiental e Urbanistico, v. 8, n. 46, p. 38-59, fev./mar. 2013.

BISOL, R. Dialética social do direito. In: SOUSA JUNIOR, J. G. (Org.). O direito achado na rua. Brasília: UnB, 1990. p. 35-37.

BOTTOMORE, T. Liberdade. In: OUTHWAITE, W.; BOTTOMORE, T. (Ed.). Dicionário 
do pensamento social do século XX. Rio de Janeiro: Zahar, 1996. p. 424-425.

BURGOS, M. Favela: uma forma de luta pelo direito à cidade. In: MELLO, M. A. et al. (Org.). Favelas Cariocas ontem e hoje. Rio de Janeiro: Garamond, 2012. p. 373-391.

BURGOS, M. et al. O Efeito UPP na Percepçáo dos Moradores das Favelas. Desigualdade \& Diversidade, Rio de Janeiro, n. 11, p. 49-98, ago./dez. 2011.

CATUSSO, J. Pluralismo jurídico: um novo paradigma para se pensar o fenômeno jurídico. Revista Eletrônica do CEJUR, Curitiba, v. 1, n. 2, p. 119-147, ago./dez. 2007.

CHAUÍ, M. Convite à filosofia. São Paulo: Ed. Ática, 2000.

CUNHA, N.; MELLO, M. A. Novos conflitos na cidade: A UPP e o processo de urbanização na favela. DILEMAS: Revista de Estudos de Conflito e Controle Social, v. 4, n. 3, p. 371-401, jul./set. 2011.

CORREA, C. A invisibilidade do direito fundamental de morar nas favelas cariocas: Modo de vida e de reproduçáo social em mercados informais e no 'direito de laje'. In: REUNIÃO BRASILEIRA DE ANTROPOLOGIA, 27, 2010, Belém. Anais da 27a RBA. Belém: ABA, 2010. 1 CD-ROM.

DURKHEIM, É. L'éducation morale. Paris: Librairie Félix Alcan, 1934.

EHRLICH, E. Fundamentos da sociologia do direito. Brasília: Ed. UnB, 1986.

ELIAS, N.; SCOTSON, J. Os estabelecidos e os outsiders. Rio de Janeiro: Jorge Zahar, 2000.

FREITAG, B. A norma social: gênese e conscientização. In: SOUSA JUNIOR, J. G. (Org.). O direito achado na rua. Brasília: UnB, 1990. p. 49-51.

JUNQUEIRA, E; RODRIGUES, J. Pasárgada revisitada. Sociologia - Problemas e Práticas, Lisboa, n. 12, p. 9-17, 1992.

KONZEN, L. Boas aventuras na Pasárgada: do pluralismo jurídico ou alternativas para uma ciência do direito pós-moderna? Prisma Jurídico, São Paulo, v. 5, p. 169-184, 2006.

LEITE, M.; OLIVEIRA, P. Violência e insegurança nas favelas cariocas: o ponto de vista dos moradores. Praia Vermelha - Estudos de Politica e Teoria Social, Rio de Janeiro, n. 13, p. 14-42, 2005.

LESSA, C. O Rio de todos os Brasis: uma reflexão em busca de auto-estima. Rio de Janeiro: Record, 2005.

LYRA FILHO, R. O Que é Direito. São Paulo: Brasiliense, 1982.

. Desordem e Processo: um posfácio explicativo. In: LYRA, D (Org.). Desordem e processo: estudos sobre o direito em homenagem a Roberto Lyra Filho. Porto Alegre: SAFE, 1986. p. 263-333.

MAGALHÃES, A. O direito das favelas no contexto da políticas de regularização. Revista Brasileira de Estudos Urbanos e Regionais, v. 11, n. 1, p. 89-103, mai. 2009.

Depois da urbanização vem a legislação. In: ENCONTRO NACIONAL DA

ANPUR, 14, 2011, Rio de Janeiro. Anais do XIV Encontro Nacional da Anpur. Rio de Janeiro: ANPUR, 2011. 1 CD-ROM.

MALISKA, M. Introdução à sociologia do direito de Eugen Ehrlich. Curitiba: Juruá, 2001.

MOUTINHO, L. Consideraçôes sobre violência, gênero e cor em Rio das Pedras. In: BURGOS, M. (Org.). A utopia da comunidade: Rio das Pedras, uma favela carioca. São Paulo: Ediçôes Loyola, 2002. p. 223-249.

O’DONNELL, G. Teoria democrática e política comparada. Dados, Rio de Janeiro, v. 42, n. 4, p. 655-690, 1999.

OLIVEIRA, L. Polícia e classes populares. Cadernos Estudos Sociais, Recife, v. 1, n. 1, p. 85-96, jan./jun. 1985.

PHARO, P. Le civisme ordinaire. Paris: Librairie des Méridiens, 1985.

QUINTANEIRO, T.; BARBOSA, M. L.; OLIVEIRA, M. Um toque de clássicos: Marx, Durkheim e Weber. Belo Horizonte: Ed. UFMG, 2002.

SADER, E. Quando novos personagens entraram em cena: experiências, falas e lutas dos trabalhadores da Grande São Paulo (1970-1980). Rio de Janeiro: Paz e Terra, 1988. 
SANTOS, B. Notas sobre a história jurídico-social de Pasárgada. In: SOUTO, C.; FALCÃO, J. (Org.). Sociologia e direito: textos básicos para a disciplina de sociologia jurídica. São Paulo: Pioneira, 1980. p. 109-117.

SARAYED-DIN, L. A ponte do Rio. Rio de Janeiro: E-papers, 2009.

SOUSA JUNIOR, J. Um direito achado na rua: o direito de morar. In: (Org.). $O$ direito achado na rua. Brasília: UnB, 1990. p. 34-35.

Direito como liberdade: $\mathrm{O}$ direito achado na rua. Experiências populares emancipatórias de criação do direito. 2008. 338 f. Tese (Doutorado em Direito) - Faculdade de Direito, Universidade de Brasília, Brasília, 2008.

TELLES, V. Sociedade civil e a construção de espaços públicos. In: DAGNINO, E. (Org.). Anos 90: política e sociedade no Brasil. São Paulo: Brasiliense, 2004. p. 91-102.

WEBER, M. Economía y sociedad. México: Fondo de Cultura, 1984.

WOLKMER, A. Pluralismo jurídico: fundamentos de uma nova cultura do direito. São Paulo: Alfa-Omega, 1997.

A B S T R A C T : Although relegated by the state, urban space in Brazilian favelas is not characterized by the absence of urban rules and controls, but a specific manifestation of these mechanisms. A socially and spatially segregated population -- which knows little of written laws, but knows from every-day life what justice and legality mean and was able to independently structure the production of urban space they inhabit -- rights do not relate only to securities listed on law and institutions, but to the way in which social relations are structured. As an effect of the void left by the lack of state-control structures, it was able to organize itself creating its own structures of control and urban-order maintenance, which -- in addition to providing some managerial independence -- show themselves much more appropriate to the conditions and characteristics of the space it occupies than their formal equivalents.

K E Y W O R D S : slums; urban space; informality; urban illegality; production of space; urban practices; law. 